\title{
O CICLO DE POLÍTICAS EM CONTEXTOS DA EDUCAÇÃO EM PRISÃO
}

\author{
Selma dos Santos ${ }^{1}$ \\ http://orcid.org/0000-0003-3791-1281 \\ Universidade Estadual de Feira de Santana \\ Eduardo José Nunes Fernandes ${ }^{2}$ \\ http://orcid.org/0000-0002-9358-8039 \\ Universidade do Estado da Bahia
}

\section{RESUMO:}

O presente artigo é baseado nos estudos de Jefferson Mainardes, que utiliza a abordagem do ciclo de políticas, proposta pelos pesquisadores ingleses Stephen J. Ball e Richard Bowe, e irá discutir contextos da educação em prisão. São cinco contextos previstos na abordagem, destacados por Mainardes: o da influência (em que as políticas públicas são iniciadas e os discursos construídos pelos grupos de interesse); o da produção do texto (é o momento da confecção dos documentos normativos); o da prática (onde a política é interpretada e recriada); o dos resultados/efeitos (procura avaliar os impactos da política frente às desigualdades existentes); e o de estratégia política (visa identificar estratégias para lidar com as desigualdades detectadas). O objetivo deste artigo é analisar o ciclo de políticas da educação em prisão na perspectiva de diferenciar educação prisional/carcerária de educação da e na prisão. Portanto, pretende-se elucidar o contexto de influência que possibilitou a emergência do discurso da educação em prisão, apreciar o contexto de produção do texto por meio da discussão de dispositivos políticos e normativos sobre o atendimento educacional aos privados de liberdade, ilustrar o contexto político da prática da educação em prisão, avaliar o contexto dos resultados/efeitos dos impactos da política frente às desigualdades existentes e, por fim, identificar o contexto de estratégia política para lidar com as desigualdades detectadas.

Palavras-chave: Ciclo de políticas. Educação em prisão. Legislação. Remição pela leitura. Políticas públicas educacionais.

\section{ABSTRACT:}

\section{THE CYCLE OF POLICIES IN CONTEXTS OF EDUCATION IN PRISON}

This article based on the studies by Jefferson Mainardes that uses the cycle of policies approach, proposed by the british researchers Stephen J. Ball and Richard Bowe, will be applied in contexts of education in prison. There are five contexts foreseen in the approach, highlighted by Mainardes: the one of influence (in which public policies are initiated and speeches constructed by interest groups); the one of the text production (it is the moment of making the normative documents); that of practice (where the policy is interpreted and recreated); that of results / effects (it seeks to rate the impacts of the policy with regard to existing inequalities); and the one of political strategy (that aims to identify strategies to deal with the detected inequalities). This article objective is to analyze the cycle of policies of education in prison in the perspective of distinguishing prison/jail education from education of and in the prison.

\footnotetext{
1 Universidade Estadual de Feira de Santana (UEFS). Professora assistente da UEFS. Doutoranda em Educação e Contemporaneidade - PPGEduc (UNEB). Membro do Grupo de Pesquisa Teoria Social e Projeto Pedagógico - TSPPP. Membro do Núcleo de Pesquisa Formação de Professores - NUFOP (UEFS). E-mail: selmapibiduefs@gmail.com

2 Universidade do Estado da Bahia (UNEB). Professor adjunto da UNEB. Professor do Programa de Pós-graduação em Educação e Contemporaneidade - PPGEduC (UNEB). Vice coordenador do Grupo de Pesquisa Teoria Social e Projeto Pedagógico. E-mail: eduardojosf2@gmail.com
} 
Therefore, it is intended to elucidate the context of influence that made possible the emergence of the discourse of education in prison, to appreciate the context of text production through the discussion of political and normative mechanisms on educational assistance to the deprived of liberty, to illustrate the political context from the practice of education in prison, evaluate the context of the results / effects of the impacts of the policy with regard to existing inequalities and, finally, identify the context of political strategy to deal with the detected inequalities.

Keywords: Policy cycle. Education in prison. Legislation. Remission by reading. Educational public policies.

\section{RESUMEN:}

\section{ELCICLODE POLÍTICASENCONTEXTOSDEEDUCACIÓNENPRISIÓN}

Este artículo se basa en los estudios de Jefferson Mainardes, quien utiliza el enfoque del ciclo de políticas, propuesto por los investigadores ingleses Stephen J. Ball y Richard Bowe, y analizará los contextos educativos penitenciarios. Hay cinco contextos previstos en el enfoque, destacado por Mainardes: el de influencia (en el que se inician las políticas públicas y los discursos construidos por los grupos de interés); la producción del texto (es el momento de hacer los documentos normativos); el de la práctica (donde se interpreta y recrea la política); el de resultados / efectos (busca evaluar los impactos de la política ante las desigualdades existentes); y el de estrategia política (tiene como objetivo identificar estrategias para hacer frente a las desigualdades detectadas). El objetivo de este artículo es analizar el ciclo de políticas de educación en prisión con miras a diferenciar la educación carcelaria / carcelaria de la educación carcelaria. Por tanto, se pretende dilucidar el contexto de influencia que posibilitó el surgimiento del discurso de la educación en prisión, apreciar el contexto de producción de textos a través de la discusión de disposiciones políticas y normativas sobre la asistencia educativa a los privados de libertad, para ilustrar el contexto político. desde la práctica de la educación penitenciaria, evaluar el contexto de los resultados / efectos de los impactos de la política ante las desigualdades existentes y, finalmente, identificar el contexto de la estrategia política para atender las desigualdades detectadas.

Palabras clave: Ciclo de políticas. Educación en prisión. Legislación. Remisión por lectura. Políticas públicas educativas.

\section{Introdução}

Fundamentados em abordagens pós-estruturalistas, que consideram a "ação dos sujeitos" um aspecto crucial para a compreensão das políticas públicas (MAINARDES; FERREIRA; TELLO, 2019), e pluralistas, Stephen J. Ball e Richard Bowe propuseram, como abordagem de análise das políticas públicas, o denominado “ciclo de políticas". Esta abordagem constitui-se num referencial analítico flexível e dinâmico, que destaca a natureza complexa da política, enfatiza as relações micropolíticas e a atuação dos agentes.

O presente artigo irá explorar a proposição de Stephen J. Ball e Richard Bowe a partir dos estudos realizados por Mainardes $(2019,2018,2006$ a, b) pois o mesmo traz uma tradução dessa proposição para o contexto brasileiro nos indicando a possibilidade de aprofundamento de análise das políticas públicas a partir do "ciclo de políticas.

De acordo Mainardes (2018, p. 10), 
As ideias de Ball, incluindo a abordagem do ciclo de políticas, inscrevem-se no contexto da policy Sociology (sociologia das políticas educacionais), ou seja, o uso de teorias e métodos da sociologia para a análise de políticas. De modo geral, a sociologia das políticas pressupõe uma análise crítica das políticas (desde a sua formulação, produção do texto, atuação na prática, resultados e consequências); a necessidade de levar em consideração as consequências das políticas para classes sociais distintas; a importância de explicitar um conceito de política e de política educacional; bem como explicitar questões relacionadas ao Estado e seu papel na oferta educacional em geral e da política investigada, de modo mais específico.

A importância de uma teorização sobre Estado vem sendo debatida desde a formulação inicial da abordagem do ciclo de políticas. Os pesquisadores são desafiados a explicitar uma posição teórica acerca da concepção e do papel do Estado e de suas relações com a política investigada (MAINARDES, 2018, p. 12). [...] Além de uma concepção de Estado, é importante que o pesquisador explicite sua concepção/conceito de política educacional, o qual necessita ser coerente com a concepção de Estado e com as demais opções teórico-epistemológicas da pesquisa. (MAINARDES, 2018, p. 13).

Explicitando a concepção de Estado, devemos dizer que o cenário em que acontecem os governos brasileiros dos últimos vinte anos é de uma proposta de Estado Neoliberal, e esses governos apresentam continuidades, descontinuidades e até rupturas de políticas, mas cada um as formulam de maneira diferente. No governo do presidente Luiz Inácio Lula da Silva (2003-2010), por exemplo, a formulação de políticas públicas tinha o mérito de escutar, dialogar com os movimentos sociais e a sociedade civil organizada, em correlações de forças nem sempre contínuas. Os demais governos da história recente do Brasil, anteriores e posteriores ao PT, apresentam uma postura neoliberal com pouca participação da sociedade civil organizada, caracterizando mais fortemente a postura de não intervenção popular nas decisões sobre as políticas públicas.

Este artigo diz respeito a política de educação para os privados de liberdade, a educação em prisão. Apresentamos as características do ciclo de políticas, que, conforme Mainardes (2006b, p. 58), são: “[...] a desconstrução de conceitos e certezas do presente, engajamento crítico, busca de novas perspectivas e novos princípios explicativos, focalização de práticas cotidianas (micropolíticas), heterogeneidade e pluralismo e articulação entre macro e microcontextos". Observa ainda o estudioso que

A abordagem do ciclo das políticas permite a análise da trajetória completa de uma política, desde a sua emergência no cenário internacional, nacional e local até o contexto da prática. E ainda até o contexto dos resultados/efeitos e delineamento de possibilidades de intervenção para reduzir ou eliminar desigualdades reproduzidas pela política, sem estabelecer hierarquias entre esses 
contextos. De variadas formas, o pesquisador é estimulado a refletir sobre a totalidade da política. (MAINARDES, 2006a, p. 100)

Assim, busca-se articular os processos macro e micro na análise de políticas educacionais para educação em prisão desde a formação do discurso da política e sobre a interpretação ativa que os profissionais que atuam no contexto da prática fazem para relacionar os textos da política à prática. No contexto da política, em termos dos marcos legais, temos uma legislação em vigor que reconhece o direito subjetivo à educação de pessoas privadas de liberdade (ver organogramas). No entanto, a atuação desses marcos legais está pulverizada, visto não haver um setor específico dentro das secretarias de segurança pública e de educação com financiamento para gestar as escolas no sentido de que desenvolvam ações pedagógicas nos presídios e que ampliem o número de vagas para todos os interessados em estudar. Há uma disparidade entre os discursos e a prática, conforma Mainardes salienta nas reflexões de Bowe e Ball:

[...] A política não é feita e finalizada no momento legislativo e os textos precisam ser lidos em relação ao tempo e o local específico de sua produção. Os textos políticos são o resultado de disputas e acordos, pois os grupos que atuam dentro dos diferentes lugares da produção de textos competem para controlar as representações da política (Bowe et al, 1992). Assim, políticas são intervenções textuais, mas elas também carregam limitações materiais e possibilidades. As respostas a estes textos têm consequências reais. Estas consequências são vivenciadas dentro do terceiro contexto, o contexto da prática. É importante destacar a distinção feita por Ball (1993a) entre "política como texto" e "política como discurso". Os textos das políticas terão uma pluralidade de leituras devido à pluralidade de leitores. [...] Os textos políticos são o resultado de disputas e compromissos. A política enquanto discurso enfatiza os limites do próprio discurso. [...] (MAINARDES, 2006a, p. 97)

Mainardes (2006a, p. 98) diz que, de acordo com Ball e Bowe (BOWE et al, 1992), “o contexto da prática é o lugar onde a política é sujeita à interpretação e recriação e onde a política produz efeitos e consequências que podem representar mudanças e transformações significativas na política original".

O ciclo de políticas compreende cinco contextos: o contexto da influência (em que as políticas públicas são iniciadas e os discursos construídos pelos grupos de interesse); o contexto da produção do texto (é o momento da confecção dos documentos normativos); o contexto da prática (onde a política é interpretada e recriada); o contexto dos resultados/efeitos (procura avaliar os impactos da política frente às desigualdades existentes); o contexto de estratégia política (visa identificar estratégias para lidar com as desigualdades detectadas) (MAINARDES, 2018, 2006 a, b). Destaca-se que os cincos contextos do ciclo de políticas estão inter-relacionados, 
não se constituindo como etapas lineares, sequenciais, já que cada contexto envolve diferentes lugares e grupos de interesses.

Considerando o exposto, o presente artigo visa analisar o ciclo de políticas da educação em prisão na perspectiva de diferenciar educação prisional/carcerária de educação da e na prisão, conforme será tratada no contexto de influências. A educação prisional/carcerária é a assistência educacional desenvolvida como mera medida humanitária ou estratégia de gestão prisional que visa a diminuição de conflitos internos na administração de encarcerados. O discurso da educação em prisão é a garantia de implantação e atuação de políticas públicas de cumprimento do direito subjetivo à educação para toda população encarcerada. É a educação formal que aponta soluções para as questões educacionais dos presos, possibilitando a diminuição do tempo dentro da prisão e o retorno à sociedade com a perspectiva de reinserção social. Uma educação que se tenha clareza do diferencial na e da prisão. $N a$ : o indivíduo tem direito de ser educado no lugar onde está cumprindo pena ou aguardando-a. Da: o indivíduo tem direito a uma educação pensada desde o seu lugar e com a sua participação vinculada à sua cultura e às necessidades humanas e sociais.

Pretende-se elucidar o contexto de influência que possibilitou a emergência do discurso da educação em prisão; apreciar o contexto de produção do texto por meio da discussão de dispositivos políticos e normativos quanto ao atendimento sobre o processo educacional aos privados de liberdade; ilustrar o contexto político da prática da educação em prisão; avaliar o contexto dos resultados/efeitos dos impactos da política frente às desigualdades existentes e, por fim, identificar o contexto de estratégia política para lidar com as desigualdades detectadas.

Em vista disso, pretende-se explanar o contexto de influência que possibilitou a emergência do discurso da educação em prisão, examinar o contexto de produção do texto por meio da discussão de dispositivos políticos e normativos sobre a educação para os privados de liberdade e, por fim, informar o contexto político de uma prática - o Projeto Leitura Prazerosa visando a remição pela leitura no Conjunto Penal de Feira de Santana.

\section{$O$ contexto de influência}

Para compreender o contexto de influência na abordagem do ciclo de políticas é relevante situar como os discursos são construídos no decorrer do tempo, de modo a apontar algumas influências presentes na política investigada e elucidar as relações macro e micropolíticas (MAINARDES, 2006 a, b).

Segundo Mainardes (2006b, p. 51), é no contexto de influência [...] que os conceitos adquirem legitimidade e formam um discurso de base 
para a política. O discurso em formação algumas vezes recebe apoio e outras vezes é desafiado por princípios e argumentos mais amplos que estão exercendo influência nas arenas públicas de ação, particularmente pelos meios de comunicação social.

A expressão “educação em prisão" tem se constituído em elemento de ordem das agendas de políticas públicas contemporâneas, sendo apropriada, reinterpretada e veiculada por diversos grupos de interesse (juristas, militantes dos direitos humanos, professores, políticos de esquerda, intelectuais, pesquisadores, agentes de segurança, etc.), de acordo com os efeitos discursivos almejados. E num contexto de superlotação carcerária, aviltamento de direitos e pouca escolaridade, o discurso da "educação em prisão" emerge, nas relações de poder-saber, como um regime de verdade, ou seja, como a "solução" para quem se encontra encarcerado.

O discurso da educação em prisão "como uma expressão da educação de jovens e adultos voltada para uma população e um contexto específicos" (IRELAND, 2011, p. 25), como uma das soluções para as questões educacionais dos presos, possibilitando a diminuição do tempo dentro da prisão e o retorno à sociedade com a perspectiva de reinserção social.

A função da prisão, de acordo a lei de execução penal, é punir o indivíduo, proteger a sociedade e ressocializar. No processo de ressocialização entra a educação. A educação faz parte do contexto da execução penal e é tratada como mais uma assistência. Inclusive, nos últimos anos, o Ministério da Educação (MEC) e Ministério da Justiça (MJ), em diálogo, aprovaram diretrizes que tratam dessa questão da Educação para Privados de Liberdade, as Diretrizes Nacionais para a Oferta da Educação em Estabelecimentos Penais aprovadas pela Resolução nº 3, de 11 de março de 2009, do Conselho Nacional de Política Criminal e Penitenciária (CNPCP) e homologadas pelo Ministério da Educação por meio da Resolução $n^{\circ} 2$ do Conselho Nacional de Educação (CNE), de 19 de maio de 2010. A questão da educação no espaço da prisão nos chama a sair de uma ideia de educação prisional, de uma educação carcerária para defender uma educação para os sujeitos jovens, adultos e idosos que estão em situação de restrição e privação de liberdade, ou seja, precisamos reconhecer que estamos falando de uma educação de jovens e adultos, que estes indivíduos estão privados de liberdade, e precisamos pensar em uma política pública particular, levando em conta essa situação. A grande questão está na política pública a partir do indivíduo que é o demandante da política de educação de jovens e adultos. As políticas públicas de educação implementadas no sistema prisional em alguns estados começaram a partir de 2005 com a SECADI (Secretaria de Educação Continuada, Alfabetização, Diversidade e Inclusão), quando muitos documentos foram aprovados em âmbito federal. O que observamos, muitas vezes, é que são políticas improvisadas, fragmentadas e descontínuas; precisamos compreender que não estamos falando de um projeto ou programas, mas de políticas públicas para esses indivíduos. 
Já avançamos na perspectiva de que, quando se fala na educação prisional, educação carcerária, compreende-se hoje que se trata de uma educação que está no ambiente de privação ou restrição de liberdade e se vem avançando, ainda mais, quando se tem as Diretrizes aprovadas pelos Conselhos (CNPCP e CNE). Hoje se compreende que essa é uma educação para jovens e adultos que estão em situação de restrição e privação de liberdade, que neste caso está sendo implementada no ambiente prisional. Isto põe em discussão se a Educação de Jovens e Adultos, modalidade de ensino da educação básica de acordo as Diretrizes Nacionais da Educação - Lei $n^{0}$ 9394/96, responde às necessidades e características dos encarcerados.

Discute-se uma educação em prisões como especificidade para a população com restrição ou privada de liberdade. Pensa-se a educação em prisões como uma garantia de implantação e atuação de políticas públicas de cumprimento do direito subjetivo à educação para toda população carcerária, tendo a escola como prática social. Dentre os pesquisadores que defendem a escola como prática social relevante nos espaços prisionais, estão De Maeyer (2013, 2011), Ireland (2011), Julião (2020, 2016, 2009), Onofre (2017, 2016, 2013), Silva e Moreira (2011). Eles propõem a escola como espaço de possibilidades e de aprendizagens para o convívio no encarceramento e, depois, na sociedade livre. Esses autores evidenciam que a escola é um espaço importante de promoção de interações entre os sujeitos, de valorização de identidades, de culturas, de afetividade e de cidadania. Ainda, apresentam reflexões para a construção de uma educação em prisões que tem como foco os sujeitos em restrição e privação de liberdade e se posicionam contrários à educação nas prisões com o papel principal de 'ressocialização', de 'reingresso' na sociedade; propõem a educação ao longo da vida.

Julião $(2020$, 2016, 2009) defende que a escola deve preparar o indivíduo no processo de socialização à vida, dentro e fora da prisão. Ele entende que estamos diante do novo paradigma de execução penal (incompletude institucional) e,

[...] é fundamental que as instituições educacionais estejam realmente alinhadas com os propósitos estabelecidos, construindo e atualizando os seus projetos políticos pedagógicos [...] a escola seja da prisão e não apenas uma escola na prisão. Uma escola que cumpra as determinações legais ao mesmo tempo em que respeite as características e peculiaridades dos seus sujeitos [...] (JULIÃO, 2016, p. 35).

A escola na prisão é transcorrida por contradições. "As prisões são lugares multiculturais e nesse espaço, aprender, compreender e aceitar as diferenças será certamente muito útil" (DE MAYER, 2013, p. 42) e buscar ter em pauta os demais direitos humanos é importante para que se cumpra o papel da escola, "reconhecer a centralidade da educação, não cair na contradição de depositar nesta a responsabilidade de resolver, por si só, o problema da violência e da 
criminalidade e de 'habilitar' a pessoa privada de liberdade para sua reentrada na sociedade" (IRELAND, 2011, p. 23).

A escola nas prisões pode ser espaço diferenciado das normativas prisionais, com avanço nos direitos humanos e aprendizagens ao longo da vida. "Dar dignidade é dar confiança", "permitir a cada um reencontrar em si sua dignidade fundamental" (DE MAYER, 2013, p. 43), ação basilar de uma educação em prisão que acontece na perspectiva da e na prisão.

Aprende-se na prisão o que ali se encontra; o que ali se compartilha com os outros. Desaprende-se a ter iniciativas, a tomar decisão, entretanto, espera-se que ao sair da prisão o egresso tome iniciativas de que foi privado e viva integrado à sociedade. "Tudo isso é a educação da prisão, não a educação na prisão!” (DE MAEYER, 2013, p. 42). Fazemos um parêntese para esclarecer a educação da prisão a que estamos nos referindo é uma educação formal, a da escolarização. Pois, a "educação" informal existe dentro da prisão. Essa educação informal da prisão tem "educado" os indivíduos para atuarem no mundo do crime. Os indivíduos se articulam, se organizam e assumem papeis dentro de facção ou no controle do pavilhão, na hierarquia da convivência. "A cultura da prisão é a educação por pares, é a reprodução dos comportamentos ou a imitação dos comportamentos valorizados. É a cultura do mais forte, da desenvoltura, do silêncio, do transitório" (DE MAEYER, 2013, p. 45).

No entanto,

A educação na prisão é também a educação (em sentido largo) pelo e para o conjunto do pessoal: administração, guardas, profissionais da saúde, pessoal de serviço, etc. Toda atividade, mesmo banal que possa parecer, pode ser oportunidade de educação não formal (refeição, higiene, relações sociais, lazer, etc.). (DE MAEYER, 2013, p. 41)

Aventa-se uma educação de presos que quase sempre não passaram pelo processo da escolarização. E, sim, pelas formas de aprendizado informal das escolhas criminosas de sobrevivência no mundo (quer seja dentro da prisão, quer seja fora). A afirmação deste perfil desenha em parte a identidade da prisão brasileira, marcada por uma população reincidente. É preciso uma intervenção sólida para mudança desse perfil, é aí que entra a educação formal da prisão como política pública que possibilitará oportunidades ao indivíduo, trazendo até ele um ensino, traçando um diálogo em que ele se reconheça e enxergue na formação caminhos para saída do mundo do crime, com emprego e inserção social.

A educação na prisão como política educacional ou projeto político-pedagógico específico requer ser feita com a participação ativa dos indivíduos que estão encarcerados, porque não basta a assistência educacional ser implementada conforme a lei e as diretrizes, é necessário dialogar com quem irá participar do processo de escolarização, incentivá-los a pensar sobre a 
educação enquanto possibilidade cultural de inserção, de emancipação e convivência com os diferentes. E pensar a si mesmo como sujeito das ações que possam trazer transformações sociais e "desenvolvimento de habilidade e capacidades para estar em melhores condições de disputar oportunidades socialmente criadas" (SILVA; MOREIRA, 2011, p. 92).

As condições violentas de desumanização das condições de vida na prisão parecem tornar impossível dialogar com os presos. Mas “a presença de educação escolar nas prisões, além da garantia de um direito humano, afirma a valorização do desenvolvimento e da busca permanente de cada indivíduo em ser mais" (ONOFRE, 2016, p. 51). Contudo, é preciso avançar no sentido desse diálogo, é preciso dar um passo de superação na realidade da injustiça social, da desigualdade, da opressão, que exige transformações sociais estruturais e imprescindíveis. Os indivíduos da educação em prisões são aqueles que vivenciam os efeitos diretos dessa realidade perversa, mas que não se conformam com ela. São indivíduos em condições diferenciadas, mas a quem não deve ser negada a possibilidade de operar mudanças nas relações de convívio social. $\mathrm{O}$ respeito às diferenças, sempre plural em suas expressões, em seus sentimentos, em seus movimentos no existir, deveria ser a marca da síntese cultural da prisão a ser considerada em qualquer ação educacional.

Infelizmente, no atual contexto, a expressão desses indivíduos é quase nula e quase não se faz identificada. O processo dessa trajetória de mudança é longo e requer uma ação educativa conscientizador desenvolvida por profissionais da educação, justiça, segurança pública e egressos do sistema prisional, pesquisadores, militantes do desencarceramento, que lutam pela política de redução da prisão.

Nesse contexto, o debate está instaurado entre grupos de interesse e o Estado brasileiro. Grupos de interesse influenciados por tratados internacionais, políticas penais com viés educacionais de direitos humanos e o Estado com a perspectiva de "menos Estado, mais mercado" que não tem se ocupado com as condições materiais e sociais dos privados de liberdade, gerando a miserabilidade carcerária e a reincidência. Ademais, para a sociedade resta a insegurança por não saber lidar com a violência instaurada pela ausência de um Estado social.

Como poderá ser observado no Organograma macro e micro contextuais em políticas públicas e educação em prisão (abaixo), toda política lida com a influência de contextos macros (internacionais, nacionais, estaduais) e micros (municipais, local de execução). Os documentos internacionais - Regras Mínimas para o Tratamento de Presos (1955), Pacto Internacional de Direitos Civis e Políticos (1966), Convenção contra a Tortura e outros Tratos ou Penas Cruéis, Inumanos ou Degradantes (1975), Carta Africana dos Direitos de Homem e dos Povos (1981) - 
influenciam a organização nacional das políticas. A título de exemplo, no Brasil, a agenda dos direitos humanos tornou-se um conteúdo fundamental em busca da efetivação de relações sociais igualitárias e justas, da garantia da dignidade da pessoa humana, em comprometimento com a redução das desigualdades e com a promoção do bem-estar de todos, livre de preconceitos ou discriminação de qualquer espécie, a partir dos documentos internacionais. Com vista a assegurar os direitos dos privados de liberdade, o Conselho Nacional de Política Criminal e Penitenciária (CNPCP), Resolução no 14 de 11 de novembro de 1994, estabeleceu as Regras Mínimas para o Tratamento de Presos no Brasil. E, paralelo no contexto brasileiro a prisão contemporânea está sob a influência das políticas de combate à criminalidade (lei antidrogas e criminalização da pobreza) importada dos Estados Unidos da América.

Assim, percebemos as influências discursivas dos documentos internacionais macros contextuais na elaboração dos documentos nacional, estaduais, municipais e específicos para o atendimento de privados de liberdade em um conjunto penal.

Figura 1. Organigrama macro e micro contextuais de políticas públicas de educação em prisão.

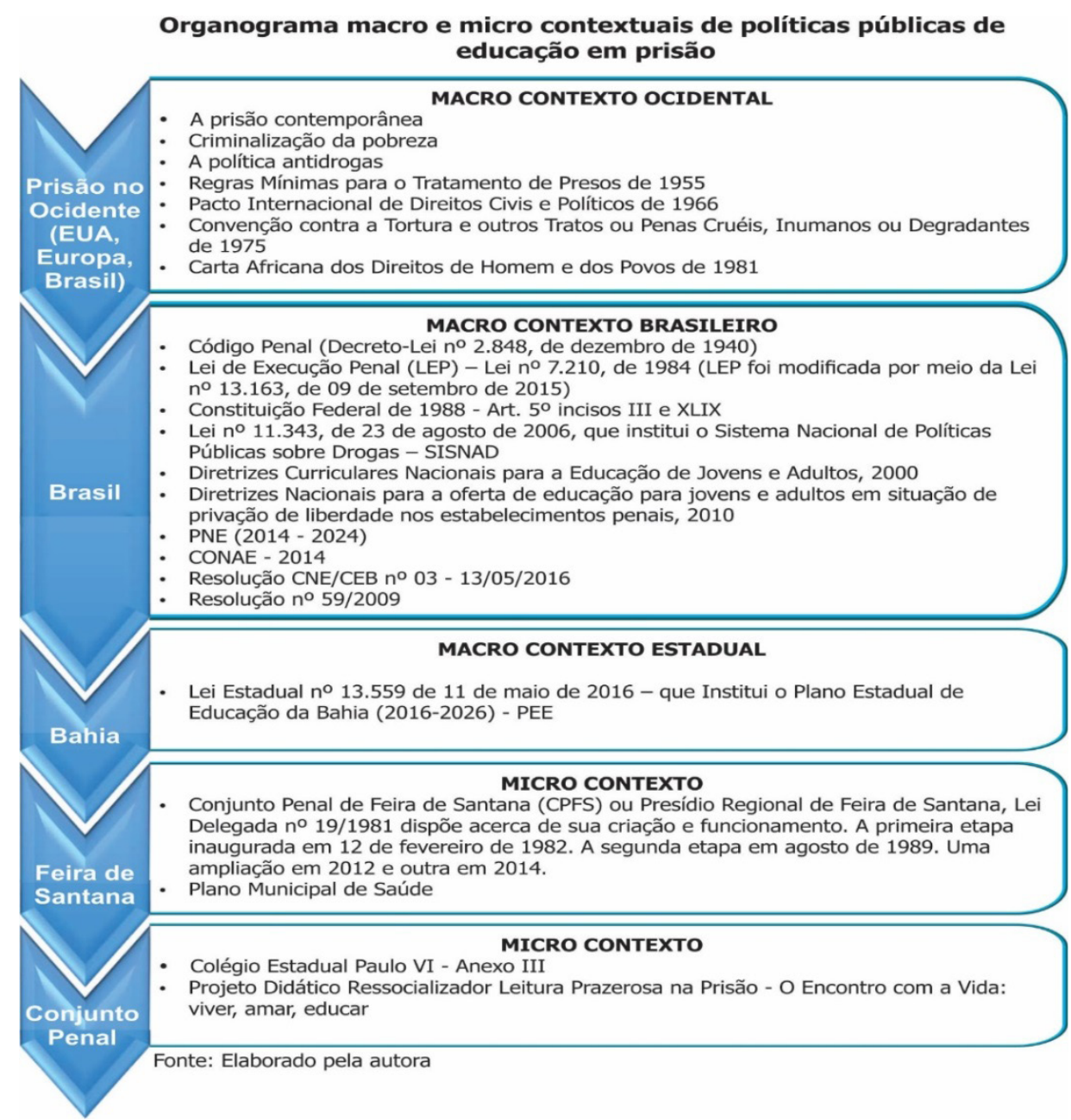

Fonte. Elaborado pela autora. 
E, acerca das relações de contexto de influências macro e micro, para que não tenhamos uma visão ingênua, é bom deixar claro que muitos acordos que o Brasil assina não passam de um ato meramente burocrático, forçoso em função da dependência financeira ou política do país, mas sem que haja de fato a intenção política de cumprir com o que está sendo acordado.

É possível que textos políticos internacionais, que estão no organograma, sofram, intencionalmente, no contexto do Brasil, alterações de enunciados para configurar outros efeitos discursivos.

Assim, as diretrizes políticas globais e as relações políticas nacionais e locais em educação na prisão se dão por meio de interconexão e interdependência. Portanto, de acordo com Mainardes (2006b, p. 52), as influências globais “[...] são sempre recontextualizadas e reinterpretadas pelos Estados-nação. [...] há uma interação dialética entre global e local. Mostram ainda que a globalização promove a migração de políticas, mas essa migração não é uma mera transposição e transferência $[\ldots]$ ".."

\section{O contexto de produção do texto}

Conforme observa ainda Mainardes (2006b, p. 52), “[...] textos não são, necessariamente, internamente coerentes e claros, e podem também ser contraditórios. Eles podem usar os termos-chave de modo diverso". Para Shiroma, Garcia e Campos (2019, p. 223), os textos podem ser “[...] caracterizados por um tom prescritivo, recorrendo-se comumente a argumentos de autoridade como estratégia para legitimação e difusão de orientações, análises, relatórios [...]”. No entanto, significados e sentidos diversos podem ser gerados pelos textos de política, abrindo margem a interpretações e reinterpretações.

O contexto de produção compreende a materialização do texto da política, de modo a atentar-se aos conceitos-chave, às inconsistências e ambiguidades presentes no texto. De logo, adverte-se acerca da "relação simbiótica" entre o contexto de influência, tratado anteriormente, e o contexto de produção do texto (MAINARDES, 2006a e b). Enquanto aquele se manifesta nos bastidores, nos interesses mais estreitos; este busca expressar a política de forma que o grande público tenha acesso a sua materialidade.

Segundo Mainardes (2006b, p. 52), “[...] os textos políticos, portanto, representam a política. Essas representações podem tomar várias formas: textos legais oficiais e textos políticos, comentários formais ou informais sobre os textos oficiais, pronunciamentos oficiais [...]”.

Em conformidade com estas orientações, na sequência, tomando como marco histórico a Lei de Execução Penal de 1984 e a Constituição Federal Brasileira de 1988, nos artigos 205, 
208, intenta-se problematizar o direito a educação para os privados de liberdade. Observa-se que as propostas políticas no campo da educação na prisão têm se caracterizado pela fragilidade no seu cumprimento. Nas últimas décadas, é possível identificar nos textos normativos e políticos da área dois discursos: um deles atribui à educação na prisão um direito; o outro, que defende a segurança interna dos presídios e, portanto, nem todos podem usufruir deste direito. Esses discursos movimentam-se entre diferentes grupos de interesses e movimentos sociais, fixando-se em argumentos diversos (jurídicos, segurança pública, pedagógicos) para justificar os posicionamentos. No entanto, segundo Mainardes (2006b, p. 54), [...] “A política como discurso estabelece limites sobre o que é permitido pensar e tem o efeito de distribuir "vozes", uma vez que somente algumas vozes serão ouvidas como legítimas e investidas de autoridade”. [...]

Na disputa pelo espaço de "voz" a ser ouvidas pode-se estabelecer conchavos para produção de textos. Em si tratando de interesses diversos e correlação de forças o texto produzido legitima opiniões diferentes e contraditórias que no contexto da prática pode se tornar inoperante e/ou com pouco resultado prático para os prováveis beneficiários, é o que possivelmente possa está acontecendo com os textos políticos-chave que tratam da educação dos privados de liberdade, que não dialogam entre si.

O Organograma textos políticos-chave da educação dos privados de liberdade referencia do contexto macro (nacional) ao contexto micro (projeto executável) a materialização da produção textual que assegura os direitos a educação pelos privados de liberdade. A partir da Lei de Execução Penal (LEP) - Lei nº7.210/1984 começa o desdobramento legislativo sobre a educação dos privados de liberdade, cada documento traz uma especificidade e amiúde reitera as conquistas possíveis. Desde setembro de 2005, quando foi firmado um Protocolo de Intenções entre os Ministérios da Educação e da Justiça, com o objetivo de conjugar esforços para a implementação de uma política nacional de educação para jovens e adultos em situação de privação de liberdade, foram desenvolvidas várias atividades no sentido de estruturar tal política, destacando-se entre elas: (1) as Resoluções; (2) a parceria com a UNESCO e o Governo do Japão; (3) Plano Estratégico de Educação no âmbito do sistema prisional; (4) a inclusão da educação como uma das metas do Programa Nacional de Segurança Pública com Cidadania; (5) a inclusão da educação nas prisões no Plano de Desenvolvimento da Educação (PDE), no Plano Nacional de Educação (PNE); (6) as matrículas nos estabelecimentos penais no censo escolar; (7) metas no Plano Estadual de Educação da Bahia; (8) Remição por trabalho, por estudo e pela leitura; (9) Provimento de execução da remição pela leitura; (10) Projetos políticos-pedagógicos e projetos didáticos. 
No organograma (abaixo) vemos documentos de referência para organização do sistema de ensino para atender as unidades prisionais. Documentos que podem subsidiar a formulação de um projeto político-pedagógico coletivamente construído e projetos didáticos que comporão parte de suas especificidades. Bem como, na elaboração mais ampla, o Plano Estadual de Educação em Prisões, das diretrizes estaduais para o tema, articulando secretarias e órgãos de governo, estabelecendo atribuições e organizando condições de oferta, fiscalização e avaliação da educação nas prisões.

Figura 2. Organigrama de textos políticos-chave que tratam da educação de privado de liberdade.

\section{Organograma de textos políticos-chave que tratam da educação de privado de liberdade}

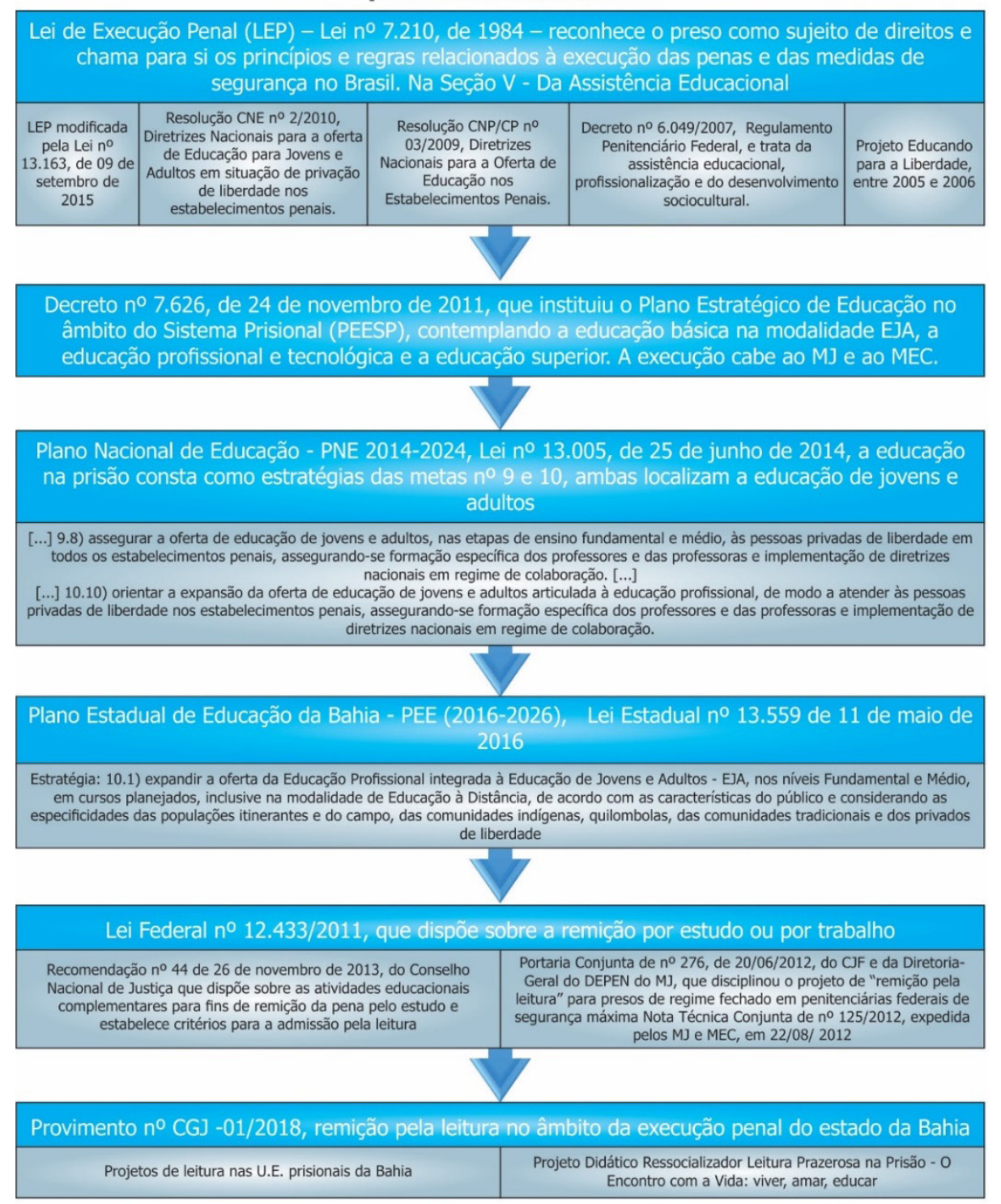

Fonte: Elaborado pela autora

Fonte. Elaborado pela autora. 
Os textos normativos principais em vigor estão no organograma (acima) e sofrem a influência na sua atuação, em especial quanto à remição de pena.

Tomados de modo isolado, os efeitos de uma política específica podem ser limitados, mas, quando efeitos gerais do conjunto de políticas de diferentes tipos são considerados, pode-se ter um panorama diferente. Esta divisão apresentada por Ball sugere-nos que a análise de uma política deve envolver o exame (a) das várias facetas e dimensões de uma política e suas implicações (por exemplo, a análise das mudanças e do impacto em/sobre currículo, pedagogia, avaliação e organização) e (b) das interfaces da política com outras políticas setoriais e como conjunto das políticas. Isso sugere ainda a necessidade de que as políticas locais ou as amostras de pesquisas sejam tomadas apenas como ponto de partida para a análise de questões mais amplas da política. (MAINARDES, 2006b, p. 54-55)

Assim, para significar e resignificar uma política pública de educação em prisão, é importante ampliar o direito a quem tem "voz"; as vozes de presos, de seus familiares e da sociedade civil organizada que militam na causa do desencarceramento precisam ser ouvidas na elaboração dos textos normativos da educação e torna-se necessário constituir um acompanhamento e avaliação dos impactos que a participação destes indivíduos na sociedade quando da elaboração de texto propositivos da política da educação.

\section{O contexto da prática}

O contexto da prática é a arena onde o texto (escrito ou não) da política é interpretado, traduzido e recriado pelos agentes institucionais (MAINARDES, 2006 a, b). É, portanto, um espaço de lutas e resistências, já que

[...] os profissionais que atuam no contexto da prática [escolas, por exemplo] não enfrentam os textos políticos como leitores ingênuos, eles vêm com suas histórias, experiências, valores e propósitos [...] Políticas serão interpretadas diferentemente uma vez que histórias, experiências, valores, propósitos e interesses são diversos. A questão é que os autores dos textos políticos não podem controlar os significados de seus textos. Partes podem ser rejeitadas, selecionadas, ignoradas, deliberadamente mal entendidas, réplicas podem ser superficiais etc. Além disso, interpretação é uma questão de disputa. Interpretações diferentes serão contestadas, uma vez que se relacionam com interesses diversos, uma ou outra interpretação predominará, embora desvios ou interpretações minoritárias possam ser importantes (BOWE et al., 1992 apud MAINARDES, 2006b, p. 53).

Nessa perspectiva, o contexto da prática na abordagem do ciclo de políticas não considera os agentes institucionais como meros receptores e executores da política vigente, mas sim, como 
sujeitos que pensam, vivenciam, recriam e dão novos sentidos à política - o que pode representar transformações significativas na proposta original (MAINARDES, $2006 \mathrm{a}, \mathrm{b}$ ).

Desta forma, neste momento, entra em cena o contexto político da prática da educação em prisão, exemplificando com o processo de atuação da política de remição pela leitura definido no texto político mas não incorporado no contexto da prática. Ainda, observam-se, nesse “microprocesso político", o contexto da prática, relações de poder e saber entre o conjunto penal e a escola.

Cada um dentro das suas medidas de forças de poder e saber busca assegurar para si o direito de execução da remição pela leitura de acordo com sua perspectiva e com pouco diálogo.

Em síntese, as contribuições do ciclo de políticas permitiram compreender a natureza complexa e controvertida da atual política de educação na prisão na perspectiva da remição pela leitura, forjada no contexto de influências político-econômicas globais, nacionais e locais, portanto, enquanto uma construção histórica, fruto das disputas entre os diferentes grupos de interesse para o estabelecimento das diretrizes e das prioridades para organização da vida do privado de liberdade.

\section{O contexto dos resultados/efeitos}

O quarto contexto do ciclo de políticas - o contexto dos resultados ou efeitos - preocupa-se com questões de justiça, igualdade e liberdade individual. A questão aqui é saber quais são os efeitos da educação para os presos e egressos do sistema penitenciário, em especial a remição pela leitura.

Os efeitos esperados referem-se a mudanças na prática ou na estrutura do tratamento ao privado de liberdade quanto ao direito à educação e o cumprimento da expectativa de que os egressos que estudaram não sejam reincidentes. Os impactos dessas mudanças nos padrões de acesso social, oportunidade e justiça social se efetivam na política pública que deve funcionar para minimizar os efeitos do estigma da condenação, carregado pelo egresso, que o impede de retornar ao normal convívio em sociedade, longe da criminalidade.

A legislação exposta no organograma reflete todo um movimento que se intensificou desde os anos 2000 e culminou com o Marco de Ação de Belém, aprovado na VI CONFINTEA (Conferência Internacional de Educação de Adultos), realizada no Brasil em 2009, na qual os estados signatários da ONU afirmam que não se pode haver exclusão da educação em virtude de encarceramento e comprometem-se a "oferecer educação de adultos nas prisões, apropriada para todos os níveis". 
No campo político, o desafio continua a ser a concretização das oportunidades de acesso a serviços educacionais nos diferentes níveis de ensino, coordenando os esforços da União, dos Estados e do Distrito Federal e articulando as responsabilidades sobre a ação governamental nas áreas de educação e justiça/segurança pública.

A concretização das oportunidades prevista a partir da Lei de Execução Penal Brasileira (Lei ${ }^{\circ} 7.210$ de 11 de julho de 1984), mesmo sendo uma das mais completas existentes no mundo, infelizmente não é colocada em prática no país. Apesar de constar no “Art. $1^{\circ} \mathrm{A}$ execução penal tem por objetivo efetivar as disposições de sentença ou decisão criminal e proporcionar condições para a harmônica integração social do condenado e do internado." e no "Art. 25. A assistência ao egresso consiste: I - na orientação e apoio para reintegrá-lo à vida em liberdade", o Estado prefere tratar as penas apenas como um meio de castigar o indivíduo pelo delito realizado. E há controvérsias jurídicas quanto à integração social, à ressocialização, pois infelizmente esta não tem sido posta em prática como deve e muito menos produzido os resultados almejados, ocasionando assim a crise que se encontra o sistema prisional.

\section{O contexto de estratégia política}

O último é o contexto de estratégia política. "Este contexto envolve a identificação de um conjunto de atividades sociais e políticas que seriam necessárias para lidar com os problemas identificados, principalmente as desigualdades criadas ou reproduzidas pela política investigada". (MAINARDES, 2006, p. 99)

No contexto da prática (micro-contexto) no Conjunto Penal de Feira de Santana, o desenvolvimento do "Projeto Didático Leitura Prazerosa" propõe ações como: leitura de Clarice Lispector; a aproximação com a realidade das mulheres encarceradas e a Unidade Escolar; processo de escuta sensível; a escrita de contos e crônicas, encenação, conversas informais. São práticas que podem resultar em descobertas importantes para se compreender a essência da política de remição pela leitura e seus resultados/efeitos sobre as participantes encarceradas. Por exemplo, durante a aplicação do projeto didático, em 2019, com a leitura prazerosa e os valores da sensibilidade crítico-criadora, uma diversidade de saberes foram despertados, podendo desencadear processo de ressocialização leitora, bem como, introduzir no mundo da leitura as principiantes. As mulheres encarceradas participantes relataram a importância de estarem na aula e pensarem um pouco sobre si, sobre a vida e sobre a leitura.

Uma política de remição pela leitura não é simplesmente implementada, mas recontextualizada, recriada na sua execução. 
O diálogo com o poder público sobre a educação em prisão perpassa pensar o modelo/ projeto de Estado no momento em que os movimentos sociais estão às margens das decisões governamentais, que mantem uma estrutura neoliberal em que os pobres não têm acesso com facilidade aos direitos garantidos em lei.

Com polêmicas jurídicas e sociais sobre a condição de ressocialização, temos uma legislação que prima pelo caráter ressocializador e é nessa perspectiva que o "Projeto Didático Ressocializador Leitura Prazerosa na Prisão - O Encontro com a Vida: viver, amar, educar" é ofertado, em cumprimento à lei como uma ação educativa para garantir a implementação da Lei Federal $n^{\circ}$ 12.433/2011, que dispõe sobre a remição de parte do tempo de execução da pena por estudo ou por trabalho.”, da Recomendação no 44 de 26 de novembro de 2013, do Conselho Nacional de Justiça que dispõe sobre as atividades educacionais complementares para fins de remição da pena pelo estudo e estabelece critérios para a admissão pela leitura, da Nota Técnica Conjunta de $n^{\circ}$ 125/2012, expedida pelos Ministérios da Justiça e da Educação, em 22 de agosto de 2012; da Portaria Conjunta de n 276 , de 20 de junho de 2012, do Conselho da Justiça Federal (CJF) e da Diretoria-Geral do Departamento Penitenciário Nacional (DEPEN) do Ministério da Justiça, que disciplinou o projeto de "remição pela leitura" para os presos de regime fechado custodiados em penitenciárias federais de segurança máxima. E, provimento $n^{\circ}$ CGJ $-01 / 2018$, remição pela leitura no âmbito da execução penal do estado da Bahia. O Projeto Didático Ressocializador "Leitura Prazerosa na Prisão - O Encontro com a Vida: viver, amar, educar" mudará a realidade? Não, mas poderá contribuir para a discussão sobre o processo de ressocialização e começar a polemizar o sistema de segurança pública em Feira de Santana - o conjunto penal veio a pedido da população como garantia de bem estar de ir e vir livremente nos espaços da cidade.

Assim, um dos efeitos cobrados para o cumprimento das políticas é o respeito à constituição federal de 1988 no que diz respeito, especificamente, a dois princípios o do artigo $5^{\circ}$ inciso III (ninguém será submetido a tortura nem a tratamento desumano ou degradante) e o do inciso XLIX (é assegurado aos presos a integridade física e moral). E aqui a interpretação dada é que todos que desejam obter uma educação escolar no presídio e não a tem vivencia o descumprimento dos princípios.

\section{Considerações finais}

Quando se fala da educação em prisões não se está buscando nada mais que assegurar a universalização da escolarização obrigatória, já que, por lei, deverá ser assegurada a formação básica comum e o respeito aos valores culturais e artísticos, nacionais e regionais; e o reconheci- 
mento e respeito à diversidade, por meio da promoção de uma educação antirracista, antissexista e antihomofóbica. É preciso garantir condições para que as políticas educacionais em prisões, concebidas, tenham atuação de forma articulada entre os sistemas de ensino e o sistema penitenciário, promovam formação integral, por meio da garantia da universalização, da expansão e da democratização, com qualidade, da educação básica.

Um desafio para a educação em prisão, que também é do Estado brasileiro, é superar os obstáculos que impediram a implantação universal da educação no sistema prisional, sobretudo aqueles obstáculos que, reiteradamente, negaram um mesmo sistema público de educação de qualidade para todos/as.

As políticas educacionais pensadas não se limitam ao Brasil. Elas sofrem as influências do contexto transnacional. Precisamos de novas narrativas sobre a educação para validar e articular o que vem sendo desenvolvido como prática pedagógica nas escolas da prisão, em especial o uso da leitura como política de remição de pena. Precisamos de uma análise crítica sobre a leitura e um discurso não utilitarista do ato de ler. Na prática, as políticas de remição pela leitura requerem maior clareza, operacionalização em todos os contextos prisionais e eliminação de constrangimentos para os participantes do processo.

Segundo Mainardes (2006b, p. 58), “pode-se afirmar que a abordagem do ciclo de políticas oferece instrumentos para uma análise crítica da trajetória de políticas e programas educacionais". Então, pensar a educação em prisão e uma prática de remição pela leitura está para além da legislação. É preciso entender a política, enquanto decisão de como fazer, uma formulação e organização das práticas educacionais no interior da prisão. Pô-la em prática no seu projeto de atuação.

\section{Referências}

DE MAEYER, Marc. A educação na prisão não é uma mera atividade. Educação \& Realidade, Porto Alegre, v. 38, n. 1, p. 33- 49, jan./mar. 2013. Disponível em: http://www.ufrgs.br/ edu realidade.

DE MAEYER, Marc. Ter tempo não basta para que alguém se decida aprender. Em Aberto, v. 24, n. 86, p. 43-55, nov. 2011.

IRELAND, Timothy D. Educação em prisões no Brasil: direito, contradições e desafios. In: Em Aberto, Brasília, v. 24, n. 86, p. 19-39, nov. 2011.

JULIÃO, Elionaldo Fernandes. A ressocialização através do estudo e do trabalho no sistema penitenciário brasileiro. 2009. 440 f. Tese (Doutorado em Ciências Sociais). Instituto de Filosofia e Ciências Humanas, Universidade do Estado do Rio de Janeiro, Rio de Janeiro, 2009. 
JULIÃO, Elionaldo Fernandes. Escola na ou da prisão? Cadernos CEDES, v. 36, p. 25-42, 2016.

JULIÃO, Elionaldo Fernandes. Sistema penitenciário brasileiro: aspectos conceituais, políticos e ideológicos da reincidência. Rio de Janeiro: Revan, 2020.

MAINARDES, Jefferson. A abordagem do ciclo de políticas e suas contribuições para a análise da trajetória de políticas educacionais. Atos de Pesquisa em Educaçãa - PPGE/ME FURB ISSN 1809- 0354 v. 1, nº 2, p. 94-105, maio/ago. 2006a. Disponível em: https://proxy. furb.br/ojs/index.php/atosdepesquisa/article/view/34. Acesso em: 27 jul. 2020.

MAINARDES, Jefferson. A abordagem do ciclo de políticas: explorando alguns desafios da sua utilização no campo da política educacional. Jornal de Políticas Educacionais. v. 12, n. 16. p. 1 - 19, ago. 2018. Disponível em: https://revistas.ufpr.br/jpe/article/view/59217. Acesso em: 27 jul. 2020.

MAINARDES, Jefferson. Abordagem do ciclo de políticas: uma contribuição para a análise de políticas educacionais. Educ. Soc. Campinas, vol. 27, n. 94, p. 47-69, jan./abr. 2006b Disponível em: http://www.cedes.unicamp.br. Acesso em 27 jul. 2020.

MAINARDES, Jefferson; BALL, Stephen J. (Orgs.) Políticas educacionais: questões e dilemas. 5. reimpr. São Paulo: Cortez, 2019.

MAINARDES, Jefferson; FERREIRA, Márcia dos Santos; TELLO, César. Análise de políticas: fundamentos e principais debates teórico-metodológicos. In: MAINARDES, Jefferson; BALL, Stephen J. Políticas educacionais: questões e dilemas. 5. reimpr. São Paulo: Cortez, 2019. p. $143-172$.

ONOFRE, Elenice Maria Cammarosano. A escola na prisão: caminhos e ousadias na formação de professores. Trabalho \& Educação, Belo Horizonte, v. 26, n. 1, p. 169-181, jan.-abr./2017.

ONOFRE, Elenice Maria Cammarosano. A prisão: instituição educativa? Cadernos CEDES, v. 36, p. 43-59, 2016.

ONOFRE, Elenice Maria Cammarosano. Políticas de formação de educadores para os espaços de restrição e de privação da liberdade. Revista Eletrônica de Educação. São Carlos, SP: UFSCar, v. 7, no. 1, p. 137-158, mai. 2013. Disponível em: http://www.reveduc.ufscar.br.

SILVA, Roberto da; MOREIRA, Fábio Aparecido. O projeto político-pedagógico para a educação em prisões. Em Aberto, Brasília, v. 24, n. 86, p. 89-103, nov. 2011.

SHIROMA, Eneida Oto; GARCIA, Rosalba Maria Cardoso; CAMPOS, Roselane Fátima. Conversão das "almas" pela liturgia da palavra: uma análise do discurso do movimento Todos pela Educação. In: MAINARDES, Jefferson; BALL, Stephen J. Políticas educacionais: questões e dilemas. 5. reimpr. São Paulo: Cortez, 2019. p. 222-248.

Recebido em: 15 de janeiro de 2021.

Publicado em: 20 de abril de 2021.

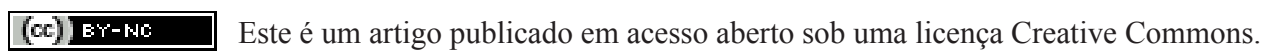

